\title{
Distribution of volatile organic compounds around a polluted river
}

\author{
${ }^{1 *}$ D. F. Juang; ${ }^{2}$ C. S. Yuan; ${ }^{1}$ S. C. Hsueh; ${ }^{1}$ L. J. Chiou \\ ${ }^{1}$ Department of Health Business Administration, Meiho Institute of Technology, 24F, 230, Ming Chuan Second Road, \\ Kaohsiung City 806, Taiwan, R.O.C. \\ ${ }^{2}$ Institute of Environmental Engineering, National Sun Yat-Sen University, 70 Lienhai Road, Kaohsiung 80424, \\ Taiwan, R.O.C.
}

Received 3 September 2008; $\quad$ revised 19 October 2008; accepted 27 November 2008; available online 10 December 2008

\begin{abstract}
The objectives of this study were to investigate the species and the concentration distribution of volatile organic compounds around a heavily polluted river. Air samples were collected seasonally at different locations near the polluted river. Samples were then analyzed by gas chromatography (electron capture detector for chlorinated organic compounds and flame ionization detector for ordinary hydrocarbons). The data was then analyzed by the statistical product and service solutions software. The results showed that total of 26 species of volatile organic compounds were identified. Each individual had its own concentration distribution pattern at different seasons and aliphatic volatile organic compounds displayed much higher concentrations than most benzenoic volatile organic compounds. In aliphatic volatile organic compounds, 1,2-dibromo-3-chloropropane, hexachlorobutadiene and 1,2dibromoetane had much higher concentrations at the nearby environment of the river and they have been claimed to be carcinogenic to some experimental animals and possibly to human. Therefore, It is in doubt that for a long term, the volatile organic compounds evaporating out of the stream may threat the health of the residents living very close to the river. The concentrations of tetrachloroethene, 1,1,2,2-tetrachloroethane, hexachlorobutadiene, dibromoetane, dichlorobenzene and sec-butylbenzene appeared at the nearby environment of the river had significant correlations ( $\mathrm{P}$ $<0.05$ ) with those of each other or many other volatile organic compounds.
\end{abstract}

Key words: Carcinogen, chlorinated hydrocarbons, morbidity rate, river water

\section{INTRODUCTION}

Fong Shan stream, a heavily polluted river, is located in the south of Taiwan with the total length of about $17 \mathrm{~km}$. This river has received domestic and agricultural wastewaters for many years. Many industries such as leather, steel, chemical, lumber, electrical, pulp and plastic industries were located mostly along the upstream riversides of Fong Shan stream. They might have discharged the wastewater into the river and caused water pollution. Since the wastewater discharged by those industries could contain some hazardous volatile organic compounds (VOCs), it is also possible that for a long term VOCs around the river might affect the health of the residents living along the riverside (Sacks and Akard, 1994). When VOCs are oxidized in the presence of oxides of nitrogen, they lead to the formation of photochemical smog, harmful to humans, animals and

*Corresponding Author Email: x2060@email.meiho.edu.tw Tel.: +886 8779 9821; Fax: +886 87780673 vegetation (Lewis and Davies, 1998). For example, the major effects of 1,2-dibromoetane (1,2-DBE) on human included respiratory tract, nervous system, kidney, etc. Ott et al. (1980) studied the mortality rates on 161 persons who had exposed to 1,2-DBE for a long term and only found 2-5 persons died from cancer. Ter Haar (1980) studied 4 groups of workers and did not find any increase in mortality rates for those who were exposed to 1,2-DBE as well. The exposure of human to 1,1,2,2-tetrachloroethane (1,1,2,2-TTCE) might affect the functions of liver and kidney. The inhalation of 1,2,4-trichlorobenzene (1,2,4-TCB) may cause negative effects on liver, kidney, lung, central nervous system and blood system (Danse et al., 1984). Many researchers reported that the growth of fish, shell, bacteria, etc. in river could be affected while the concentration of 1,1,2,2-TTCE in river water was higher than $1 \mathrm{mg} / \mathrm{L}$ (Smith et al., 1991; Nichols et al., 1993). Sec-butylbenzene and tert-butylbenzene may 
cause negative effects on eyes, mucous membrane and lung. Meanwhile, the long term exposure of pisopropyltoluene may also cause negative effects on liver and kidney of human (USEPA, 1997). Bromobenzene may cause liver and nervous system damage and isopropylbenzene may cause negative effects on lung and central nervous system as well. IARC (1999) has claimed 1,2-dibromo-3chloropropane (DBCP) to be possibly carcinogenic to humans such as lung cancer, liver cancer, bladder cancer, cervix cancer, etc. Long term exposure of 1,2dichlorobenzene (1,2-DCB) may also cause negative effects on kidney or blood system (IPCS, 2003), although the carcinogenicity of 1,2-DCB to human is still not classifiable. Therefore, as far as the public health is concerned, possible volatile organic compounds (VOCs) existing around a heavily polluted river were identified first and their concentration distribution characteristics were also discussed in the article.

Most researchers investigated the volatile organic compounds in surface water and it was difficult to find research references regarding the study of VOCs evaporating out of the water surface of river. Yamamoto et al. (1997) investigated the levels and the distribution of 55 VOCs on water samples from 30 sites within the urban rivers and estuaries of Osaka, Japan. They reported that 40 VOCs were detected and the levels of dichloromethane (DCM) were higher at all the sampling sites. DCM, toluene, 1,2,3trichloropropane (PCP) and 1,4-dichlorobenzene (1,4DCB) were detected in many sites sometimes at levels above $100 \mu \mathrm{g} / \mathrm{L}$. 1,1,1-trichloroethane (1,1,1-TCE), benzene, trichloroethene (TCE), 1,2-dichloropropane (1,2-DCP), tetrachloroethene (PERC), chlorobenzene (CB), ethylbenzene (EB), 1,3-xylene, 1,4-xylene, 1,2DCB and 1,2,4-trimethylbenzene (1,2,4-TMB) were found at the level of $10 \mu \mathrm{g} / \mathrm{L}$ or more.

Kostopoulou et al. (2000) investigated the most commonly encountered VOCs in the surface waters of northern Greese. They found chloroform, carbon tetrachloride, bromodichloromethane (BDCM), chlorodibromomethane (CDBM), TCE and PERC. Rathbun (2000) discussed the processes affecting the transport behavior and fate of VOCs in streams and concluded that water velocity, flow depth and water temperature of the streams would be the major factors affecting the volatilization of VOCs. Since vinyl chloride (VC) has been reported to be carcinogenic to human,Yamamoto et al. (2001) also studied its contamination in shallow urban rivers in Osaka, Japan. They concluded that VC concentrations ranged from below detection limit to $55.60 \mu \mathrm{g} / \mathrm{L}$ with the mean of $3.35 \mu \mathrm{g} / \mathrm{L}$ and the standard deviation of $5.96 \mu \mathrm{g} / \mathrm{L}$. They also found that the concentrations of cis-1,2dichloroethene (c-DCE), PERC and TCE were significantly correlated with VC concentrations in the rivers with the relative ratios of about 1:2.7:1.5:0.31 (VC:C-DCE:PERC:TCE). The concentrations of the four VOCs decreased with distance down the river. Nikolaou et al. (2002) detected 15 kinds of VOCs in surface water and 31 types of VOCs in wastewater. However, they concluded that the concentrations of these observed VOCs did not exceed the guideline values of European Community. The concentrations of VOCs in the rivers were mostly in the range between ND (not detectable concentration) and 6.7 $\mu \mathrm{g} / \mathrm{L}$. The concentrations of VOCs were mostly in the range between ND and $2.0 \mu \mathrm{g} / \mathrm{L}$ in the lakes and in the range between ND and $664 \mu \mathrm{g} / \mathrm{L}$ in wastewater.

The Sewer Department of Kaohsiung Municipal Government (2003) investigated the VOCs in the water of Chuen-Tsen river which is actually the downstream section of Fong Shan stream while entering the Kaohsiung City of Taiwan and concluded that the VOCs primarily found in the upstream river water were volatile aromatic compounds such as methyl benzene (toluene) (1.10-3.55 $\mu \mathrm{g} / \mathrm{L}$ in average), ethylbenzene (2.92-16.10 $\mu \mathrm{g} / \mathrm{L}$ in average), m,p-xylene (4.50-13.60 $\mu \mathrm{g} /$ $\mathrm{L}$ in average), o-xylene (2.48-9.60 $\mu \mathrm{g} / \mathrm{L}$ in average) etc. Meanwhile, the chlorinated VOCs such as 1,2dichloroethane (1,2-DCA) (up to $42.7 \mu \mathrm{g} / \mathrm{L}$ ), chloroethylene (up to $9.60 \mu \mathrm{g} / \mathrm{L}$ ), cis-1,2dichloroethylene, tetrachloroethene (PERC), bromodichloromethane (BDCM), 1,1,2-trichloroethane (1,1,2-TCE), chloroform, chloroethane, methyl t-butyl ether, etc. were primarily found in the downstream river water.

Some researchers also studied the VOCs in groundwater. Watson et al. (2003) investigated the sources of earthy/musty VOCs, including geosmin, 2-methylisoborneol (MIB), 2,4,6-trichloroanisole (2,4,6-TCA), 2-isopropyl-3-methoxypyrazine and 2isobutyl-3-methoxypyrazine from the pulp and paper mill in Canada. They found very high concentrations (between 1,600 and 128,000 ng/L) 
of geosmin in water samples taken from activated bioreactor. The concentrations of MIB in the sludge samples of bioreactor were between 25 and 24,000 ng/L. Rivett et al. (2005) reported that TCE, PERC, 1,1,1-TCA, TCM (trichloromethane) and c-DCE were the most frequently found chlorinated VOCs in the groundwater aquifer in Birmingham, UK. Recently, Ellis and Rivett (2007) assessed the impact of urban VOC contaminated groundwater on the water quality of river Tame in UK. They concluded that the overall surface water quality deterioration in river Tame was not very significant, although Tame valley had a long industrial history and significant VOC aquifer contamination. However, they found that groundwater aquifer contained significant chlorinated VOC contamination. Many kinds of chlorinated VOCs were found, including TCE, TCA, PERC, DCE, 1,1-DCA, TCM, etc. Their maximum concentrations were about in the range of 0.1 to 100 $\mu \mathrm{g} / \mathrm{L}$.

Liu et al. (2007) measured the levels of ambient VOCs in the Pearl river delta region, China and found that alkanes constituted the largest percentage ( $>40$ $\%$ ) in mixing ratios of the quantified VOCs at six sites

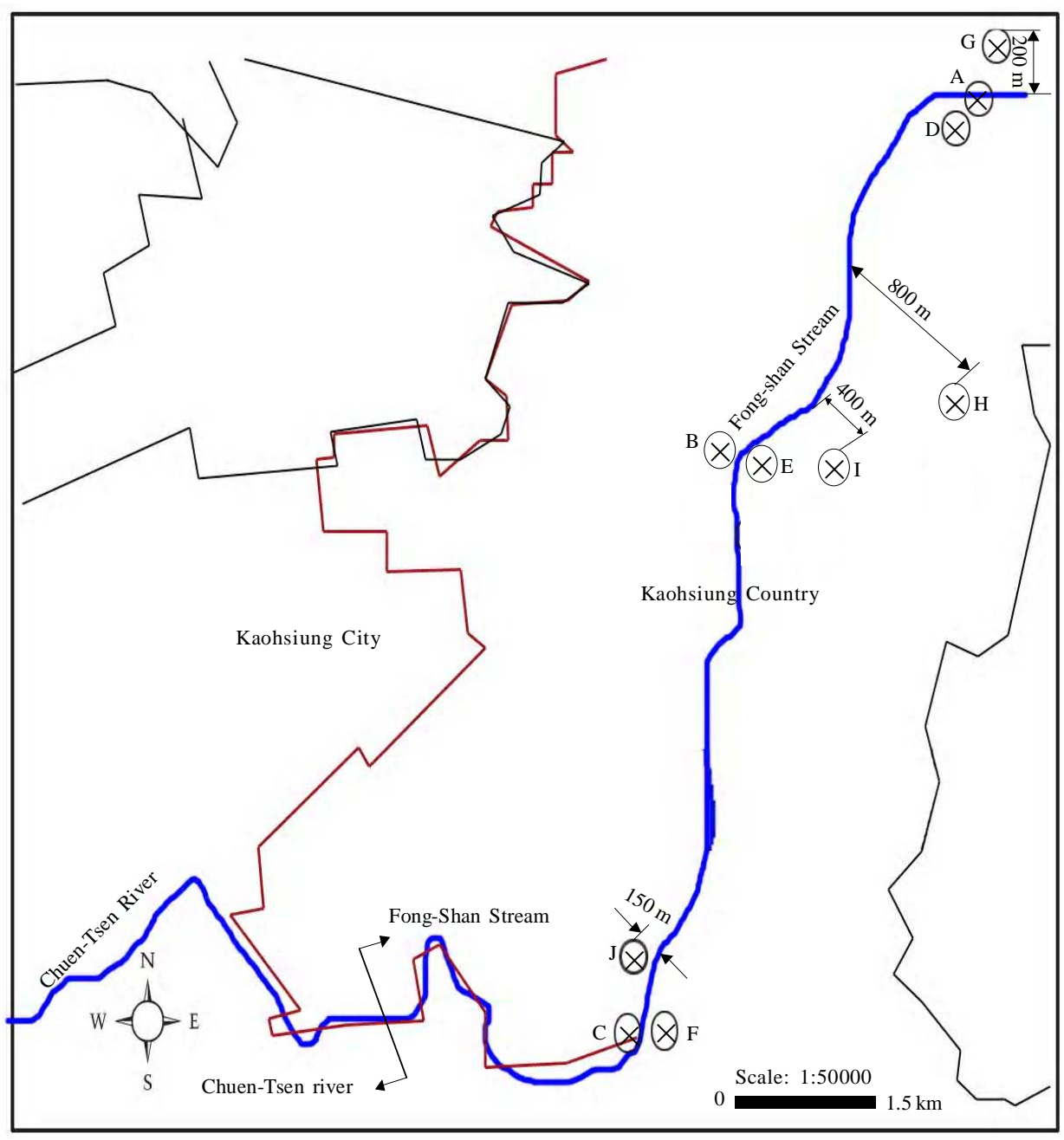

Fig. 1: Sampling locations of VOCs in the studied area 
Table 1: Sampling locations of VOCs

\begin{tabular}{cl}
\hline Sampling locations Description \\
\hline A & At the upstream river water surfaces \\
B & At the midstream river water surfaces \\
C & At the downstream river water surfaces \\
D & $\begin{array}{l}\text { At the places just beside the river and next } \\
\text { to location A } \\
\text { E }\end{array}$ \\
F & $\begin{array}{l}\text { At the places just beside the river and next } \\
\text { to location B } \\
\text { to location C }\end{array}$ \\
G & $\begin{array}{l}\text { About } 200 \mathrm{~m} \text { away from the upstream reach } \\
\text { of river } \\
\text { About } 800 \mathrm{~m} \text { away from the midstream } \\
\text { reach of river } \\
\text { About } 400 \mathrm{~m} \text { away from the midstream } \\
\text { reach of river } \\
\text { About } 200 \mathrm{~m} \text { away from the downstream } \\
\text { reach of river }\end{array}$ \\
\hline
\end{tabular}

and only one major industrial site dominated by aromatics (about $52 \%$ ).

In this study, the species and the concentration distribution of VOC evaporating out of a heavily polluted river were investigated and it is hoped that the results could be helpful in the future studies of health risk assessment on the residents living very close to the river. This study was conducted from August 2004 to July 2005 and air samples were collected around the heavily polluted Fong Shan Stream located in the south of Taiwan.

\section{MATERIALS AND METHODS}

VOCs sampling plan

The sampling locations of VOCs in this study were shown in Fig. 1 and described in Table 1. Sampling was performed seasonally and always taken during noon. The selected locations and the sampling time had less interference in air pollutants from vehicles. Since this river has received various types of industrial wastewater, it is expected that a variety of VOCs could evaporate out of the river water surface and diffuse into the nearby environment.

The air samples were taken by using Gilian air sampling pumps (model LFS-113DC) and the stainless sampling tubes were filled with Carbosieve and TenaxTA absorbents. Air sampling pumps were calibrated by a BUCK M-5 flow calibrator (flow in the range from 1-6000 mL/min) before and after use. Sampling tubes made by Supelco company were also cleaned up using nitrogen gas for $2-5 \mathrm{~h}$ at the flow rate of 50 $\mathrm{mL} / \mathrm{min}$ before use. At the sampling time air samples were pumped at a low flow rate of $100 \mathrm{~mL} / \mathrm{min}$ directly into the sampling tubes without passing through the pump body. The sampling time required for each tube was normally about 2-3 h.

All the sampling tubes were stored in a refrigerator at a temperature lower than $4{ }^{\circ} \mathrm{C}$. After the completion of sampling, all tubes were brought back to the laboratory immediately. The absorbed VOCs were purged and trapped into the carrier with highly pure nitrogen gas after thermal desorption (TD) by Tekmar aero trap desorber (Tekmar 6000) and the purged VOCs were then injected into gas chromatography for subsequent analysis (USEPA, 1994). A special floating cover placed at about $10 \mathrm{~cm}$ above the surface of river water was applied for the sampling of VOCs evaporating out of the river. Field blanks and system blanks were taken for each sampling and at least one duplicate was done for each sample as well. While VOCs samples were taken, the data regarding weather conditions such as wind speed, wind direction, temperatur and humidity was also measured and collected simultaneously.

\section{VOCs analytical methods}

After the air samples were taken at all the locations shown in Fig. 1, they were then analyzed qualitatively and quantitatively. The chlorinated hydrocarbons were analyzed by HP 5890 series A (HP 5890 SERIESII) gas chromatography and electron capture detector (GC/ECD) and the ordinary hydrocarbons were then analyzed by HP 5890 series A (HP 5890 SERIES-II) gas chromatography and flame ionization detector (GC/FID) with the application of fused silica capillary column, $70 \mathrm{~m}$ (length) $\times 0.53 \mathrm{~mm}$ (inside diameter $) \times$ 3.0 $\mu \mathrm{m}$ (film thickness) (USEPA, 1994; Nikolaou et al., 2002). During the first phase of thermal desorption, temperature was set at $-50{ }^{\circ} \mathrm{C}$ and desorption continued for $20 \mathrm{~min}$. In the second phase, the desorped samples were automatically transferred to frozen capillary traps for 4 min with the temperature down to $-170{ }^{\circ} \mathrm{C}$. Then, the samples were injected into GC for $1 \mathrm{~min}$. Finally, the VOCs samples were separated and analyzed by FID and ECD qualitatively and quantitatively.

\section{Statistical analysis}

All statistical analyses of the data were completed 
Int. J. Environ. Sci. Tech., 6 (1), 91-104, Winter 2009

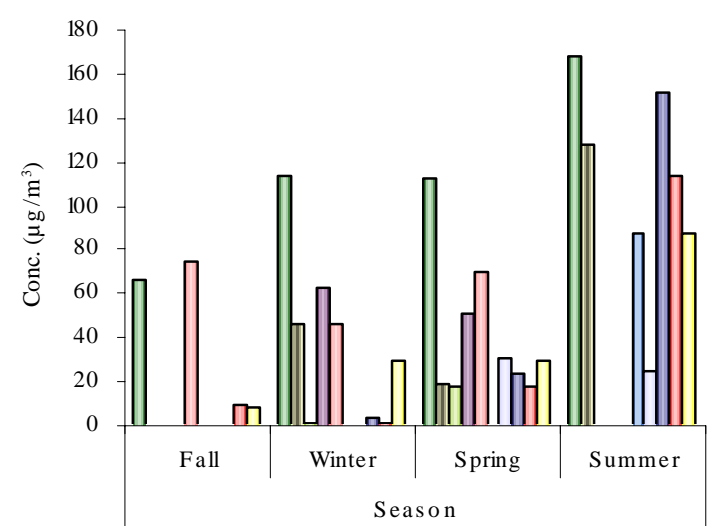

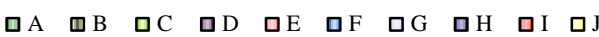

(a) Bromodichloromethane

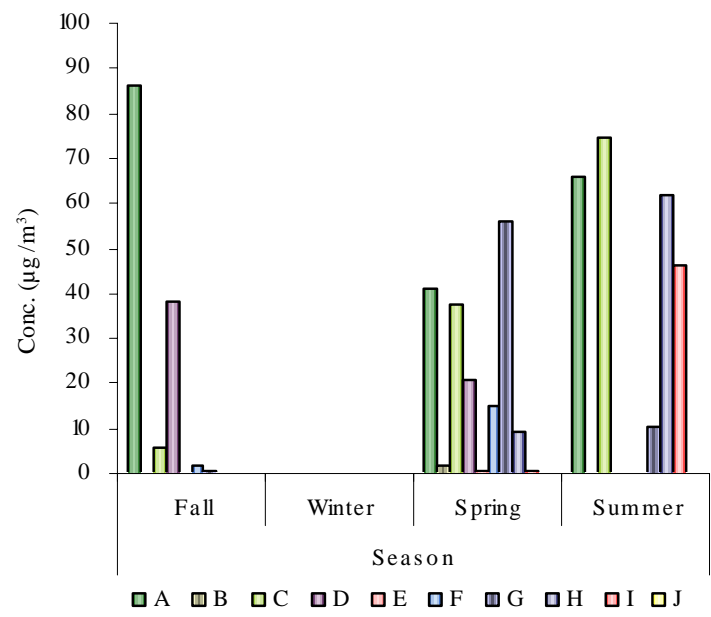

(c) Dibromomethane

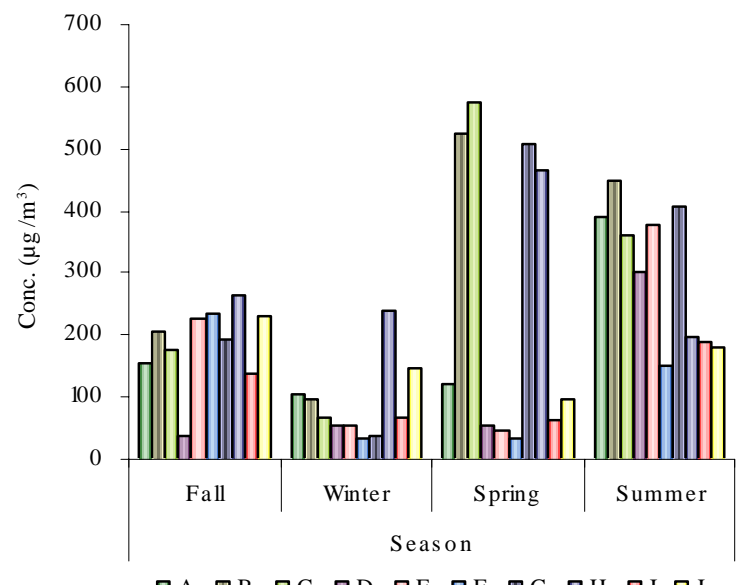

(e) 1,2-dibromo-3-chloropropane

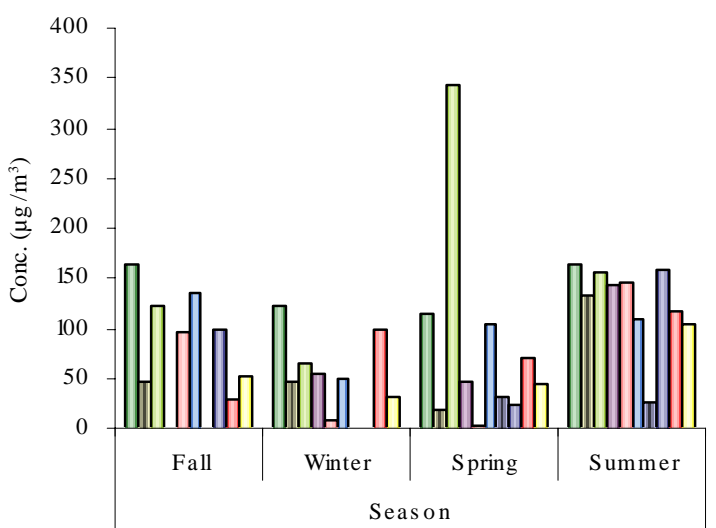

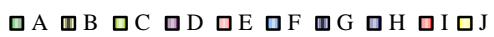

(b) Chlorodibromomethane

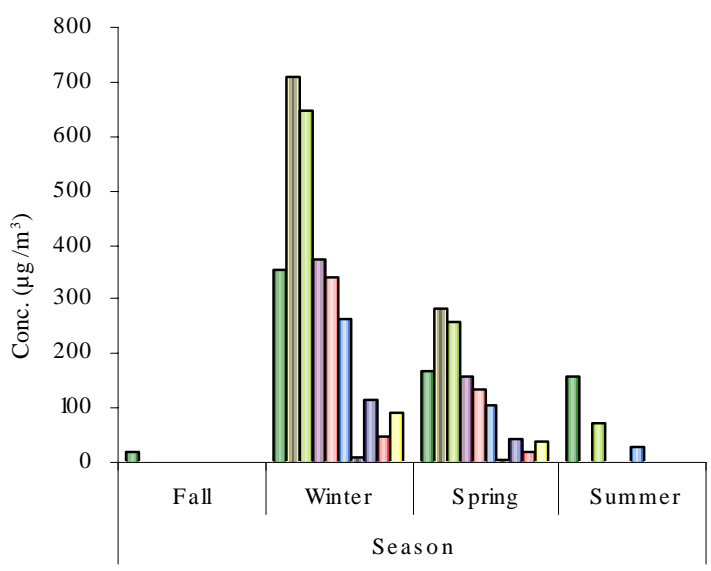

$\square$ A $\square$ B $\square$ C $\square$ D $\square$ F $\square$ G $\square$ H $\square J$

(d) 1,2-dibromoetane

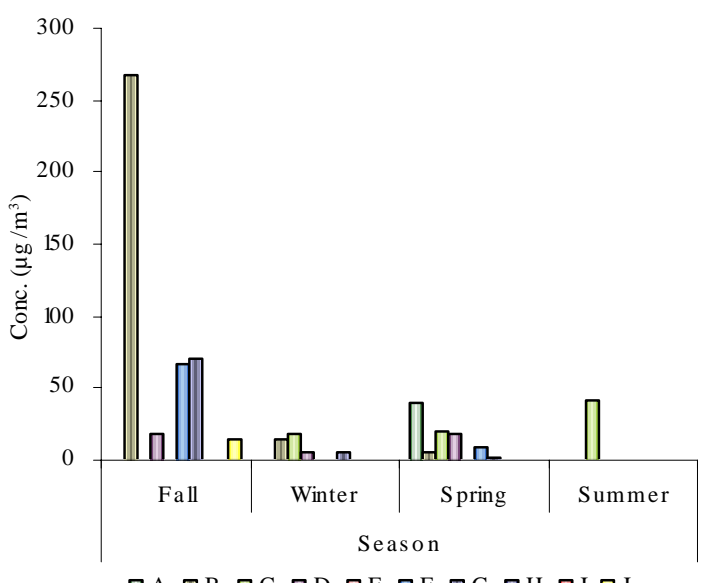

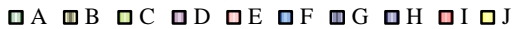

(f) 1,3-dichloropropane

Fig. 2: Concentration distribution of aliphatic VOCs at different seasons (Note: A, B, C, D, E, F, G, H, I and J are the sampling locations shown in Fig. 1) 


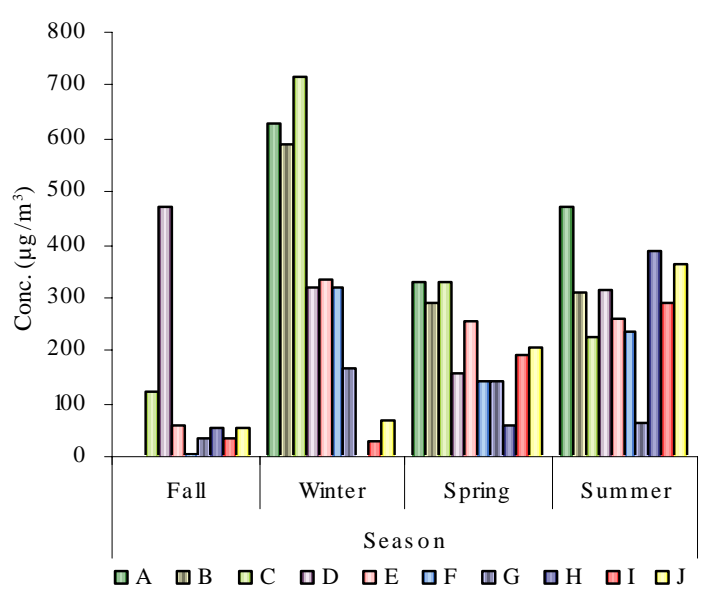

(g) Hexachlorobutadiene

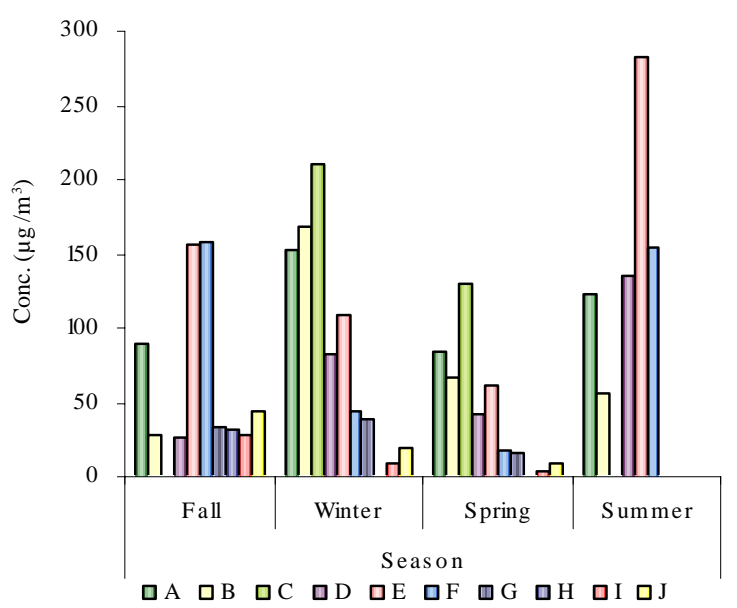

(i) 1,1,2,2-tetrachloroethane

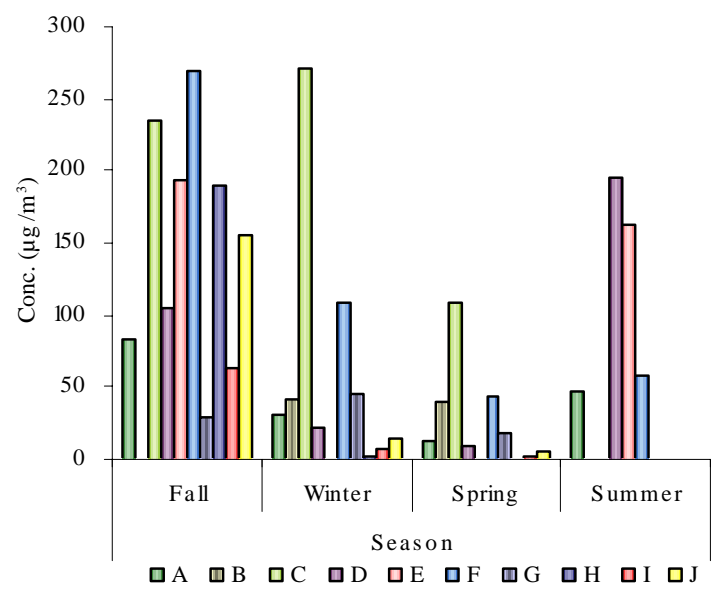

(h) Tetrachloroethene

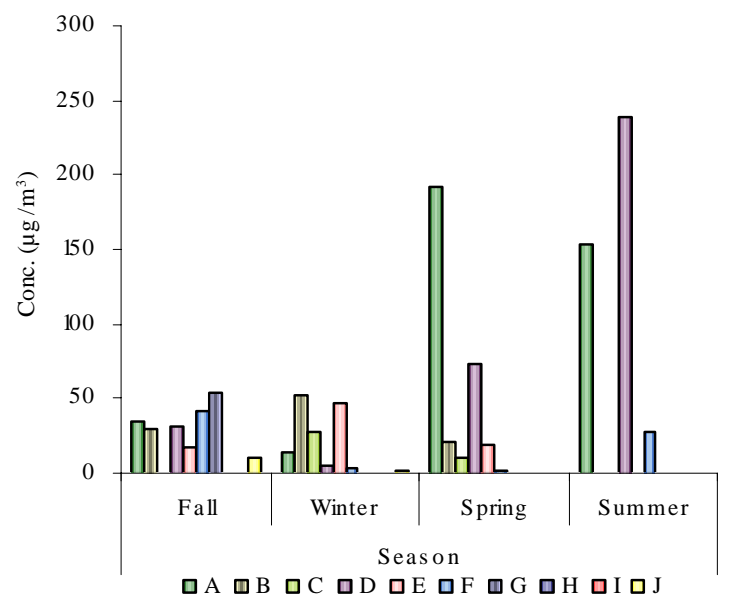

(j) 1,1,2-trichloroethane

Fig. 2 (continued): Concentration distribution of aliphatic VOCs at different seasons (Note: A, B, C, D, E, F, G, H, I and J are the sampling locations shown in Fig. 1)

using statistical product and service solutions (SPSS) software and the significance level of 0.05 was used. Except descriptive analysis, Chi-squared analysis was used to test the correlations between VOCs found in this study.

\section{RESULTS AND DISCUSSION}

Totally, 26 species of VOCs were identified including 10 species of aliphatic VOCs and 16 species of benzenoic VOCs and many of them were reported to be carcinogenic or probably carcinogenic to human. The statistical data of identified VOCs was shown in
Tables 2 and 3.

\section{Concentration distribution of aliphatic VOCs}

Fig. 2 showed that the concentration distribution of each aliphatic VOC at different sampling locations varied every season. This is possible that the industries located at the upstream of river discharged the wastewater containing different types and concentrations of VOCs into the river every season. Table 2 expressed that some aliphatic VOCs such as DBCP, hexachlorobutadiene (HCBD) and 1,2-DBE had much higher concentrations (maximum level over 550 
Int. J. Environ. Sci. Tech., 6 (1), 91-104, Winter 2009

Table 2: Statistical data of aliphatic VOCs found in the study

\begin{tabular}{|c|c|c|c|c|c|}
\hline Aliphatic VOCs & $\begin{array}{c}\text { Sample } \\
\text { size }\end{array}$ & $\begin{array}{c}\text { Concentration } \\
\text { means }\end{array}$ & ${ }^{* *} \mathrm{SD}$ & $\begin{array}{c}\text { Min. } \\
\text { concentration }\end{array}$ & $\begin{array}{c}\text { Max. } \\
\text { concentration }\end{array}$ \\
\hline Chlorodibromomethane (CDBM) & 40 & 81.823 & 67.707 & ${ }^{*} \mathrm{ND}$ & 342.867 \\
\hline Bromodichloromethane (BDCM) & 40 & 39.919 & 47.700 & ND & 168.061 \\
\hline 1,3-dichloropropane (1,3-DCP) & 40 & 15.408 & 44.306 & ND & 267.272 \\
\hline 1,1,2-trichloroethane (1,1,2-TCE or TCE) & 40 & 27.749 & 52.484 & ND & 238.400 \\
\hline 1,2-dibromo-3-chloropropane (DBCP) & 40 & 206.378 & 153.626 & 34.593 & 574.708 \\
\hline Tetrachloroethene (PERC) & 40 & 64.083 & 81.753 & ND & 270.919 \\
\hline 1,1,2,2-tetrachloroethane (1,1,2,2-TTCE or TTCE) & 40 & 65.225 & 69.196 & ND & 282.667 \\
\hline Hexachlorobutadiene (HCBD) & 40 & 225.844 & 181.956 & ND & 716.517 \\
\hline Dibromomethane (DBM) & 40 & 14.337 & 24.591 & ND & 85.960 \\
\hline 1,2-dibromoetane (1,2-DBE or DBE) & 40 & 111.195 & 172.771 & ND & 708.195 \\
\hline
\end{tabular}

Concentration unit: $\mu \mathrm{g} / \mathrm{m}^{3}$; ${ }^{*} \mathrm{ND}$ : Not detected (less than $0.001 \mu \mathrm{g} / \mathrm{m}^{3}$ ); ${ }^{* *} \mathrm{SD}$ : Standard deviation

Table 3: Statistical data of benzenoic VOCs found in the study

\begin{tabular}{lccccc}
\hline Benzenoic VOCs & $\begin{array}{c}\text { Sample } \\
\text { size }\end{array}$ & $\begin{array}{c}\text { Concentration } \\
\text { means }\end{array}$ & ${ }^{* *}$ SD & $\begin{array}{c}\text { Min. } \\
\text { concentration }\end{array}$ & $\begin{array}{c}\text { Max. } \\
\text { concentration }\end{array}$ \\
\hline Benzene & 40 & 6.176 & 23.975 & ND & 152.333 \\
Toluene & 40 & 8.682 & 14.668 & ND & 54.377 \\
m-xylene (MXYL) & 40 & 6.411 & 6.394 & ND & 24.032 \\
o-xylene (OXYL) & 40 & 13.469 & 22.697 & ND & 116.028 \\
Bromobenzene (BB) & 40 & 63.494 & 59.551 & ND & 266.888 \\
1,2-dichlorobenzene (1,2-DCB or DCB) & 40 & 63.144 & 70.285 & ND & 343.450 \\
1,2,3-trichlorobenzene (1,2,3-TCB or TCB1) & 40 & 21.281 & 38.555 & ND & 199.778 \\
1,2,4-trichlorobenzene (1,2,4-TCB or TCB2) & 40 & 38.518 & 53.044 & ND & 230.602 \\
Ethylbenzene (EB) & 40 & 7.012 & 14.731 & ND & 88.000 \\
Isopropylbenzene (IPB) & 40 & 41.591 & 45.673 & ND & 236.273 \\
1,3,5-trimethylbenzene (1,3,5-TMB or TMB) & 40 & 10.611 & 20.651 & ND & 107.496 \\
tert-butylbenzene (tert-BB) & 40 & 63.963 & 56.852 & ND & 305.860 \\
sec-butylbenzene (sec-BB) & 40 & 90.930 & 94.392 & ND & 360.297 \\
p-isopropyltoluene (p-IPT) & 40 & 26.341 & 24.086 & ND & 89.778 \\
n-propylbenzene (n-PB) & 40 & 6.827 & 13.546 & ND & 76.559 \\
Naphthalene (NAPH) & 40 & 30.621 & 48.200 & ND & 225.132 \\
\hline Cor & & & & \\
\hline
\end{tabular}

Concentration unit: $\mu \mathrm{g} / \mathrm{m}^{3} ;{ }^{*} \mathrm{ND}$ : Not detected (less than $0.001 \mu \mathrm{g} / \mathrm{m}^{3}$ ); ${ }^{* *} \mathrm{SD}$ : Standard deviation 
$\mu \mathrm{g} / \mathrm{m}^{3}$ ) at the nearby environment of Fong Shan stream than others and their concentration means were $206.378 \mu \mathrm{g} / \mathrm{m}^{3}, 225.844 \mu \mathrm{g} / \mathrm{m}^{3}$ and $111.195 \mu \mathrm{g} / \mathrm{m}^{3}$, respectively. Meanwhile, DBCP, HCBD and 1,2-DBE were seen to have much higher concentrations in spring and summer, in winter and summer and in winter, respectively. It is noted that these three VOCs have been claimed to be carcinogenic to some experimental animals and possibly carcinogenic to human (ATSDR, 2005).

Although the concentration of DBCP in the air is normally very low (ATSDR and USPHS, 1992), OSHA (1989) has defined that the exposure level of this VOC should be less than $1 \mathrm{ppb}$ (about $9.55 \mu \mathrm{g} / \mathrm{m}^{3}$ ) in $8 \mathrm{~h}$ per day and over 40 weeks. However, for the people living in the areas close to a site with the air pollution of DBCP, it is very possible to inhale this VOC easily. IARC (1999) has claimed it to be possibly carcinogenic to humans such as lung cancer, liver cancer, bladder cancer, cervix cancer, etc. It needs to pay attention that the concentration of DBCP at the nearby environment of Fong Shan stream was so high (Table 2) and it could be identified at almost every sampling locations every season (Fig. 2).

According to the regulations of occupational safety and hygiene, the limiting level of HCBD in the air of working places in Taiwan is $210 \mu \mathrm{g} / \mathrm{m}^{3}$. Since the concentrations of HCBD identified at the nearby environment of Fong Shan stream were higher than this limit, future studies on the health risk assessment for the residents living very close to this stream may be interesting.

Singh et al. (1982) measured the concentrations of 1,2-DBE in the air of seven cities in USA and obtained the average levels between 0.015 and $0.46 \mu \mathrm{g} / \mathrm{m}^{3}$, with the maximum level of $2.83 \mu \mathrm{g} / \mathrm{m}^{3}$. Apparently, the concentration of 1,2-DBE found in this study was much higher than that maximum level. However, the occupational exposure level defined by the National Institute of Occupational Safety and Health (NIOSH) of USA is $1.0 \mathrm{mg} / \mathrm{m}^{3}$ which is still higher than those observed at the nearby environment of Fong Shan stream.

CDBM was popularly found in surface waters usually present in outside air at a level less than $0.05 \mu \mathrm{g} / \mathrm{m}^{3}$. The levels of BDCM in air and surface waters were usually quite low (always less than 0.8 $\mu \mathrm{g} / \mathrm{m}^{3}$ ) with the averages of 4 and $200 \mu \mathrm{g} / \mathrm{m}^{3}$, respectively (ATSDR, 2005). However, the concentrations of both CDBM and BDCM found in this study (Fig. 2) were much higher than those reported values, especially in summer. It should be noted that both VOCs have also been claimed to be carcinogenic to some experimental animals and possibly carcinogenic to human (ATSDR, 2005). USEPA reported that the middle half levels (25th to 75th percentile) of PERC in indoor and outdoor air were ranged between 1 and $10 \mu \mathrm{g} / \mathrm{m}^{3}$ (NYSDH, 2003).

Apparently, the PERC at the nearby environment of Fong Shan stream was found to have much higher concentrations than those reported values (Fig. 2), especially in fall. Again, PERC has been claimed to be possibly carcinogenic to human (Beck et al., 2000).

1,1,2,2-TTCE was highly volatile and it could enter the river through the discharge of industrial wastewater and evaporate out of the river easily (Kaiser and Comba, 1983).

The major exposure ways of VOC for human were indoor and outdoor inhalation. In the air of residential area in USA and Canada, the concentration of 1,1,2,2TTCE was normally detected to be lower than $0.1 \mu \mathrm{g} /$ $\mathrm{m}^{3}$ (IPCS, 1994). In this study, the levels of 1,1,2,2TTCE were between ND and $210 \mu \mathrm{g} / \mathrm{m}^{3}$, especially in summer and fall with the concentration over $150 \mu \mathrm{g} /$ $\mathrm{m}^{3}$ at the nearby environment of Fong Shan stream. Although the concentration of 1,1,2,2-TTCE was up to about $283 \mu \mathrm{g} / \mathrm{m}^{3}$, further studies should be required to confirm whether its concentration in river water will affect the growth of fish, shell, bacteria, etc. However, according to the regulations of Occupational Safety and Hygiene in Taiwan, the limiting level of 1,1,2,2-TTCE in the air of working places is $6,900 \mu \mathrm{g} / \mathrm{m}^{3}$ which is much higher than the level found in this study.

\section{Concentration distribution of benzenoic VOCs}

Although 16 species of benzenoic VOCs were identified, most of them appeared to be much lower at the nearby environment of Fong Shan stream than aliphatic VOCs. The concentration distribution of benzenoic VOCs was illustrated in Fig. 3. Most of benzenoic VOCs showed higher concentration at the nearby environment of Fong Shan stream in fall or winter such as 1,2-DCB, 1,2,4-trichlorobenzene (1,2,4TCB), toluene, m-xylene, o-xylene, isopropylbenzene (IPB), bromobenzene (BB), 1,3,5-trimethylbenzene 
Int. J. Environ. Sci. Tech., 6 (1), 91-104, Winter 2009

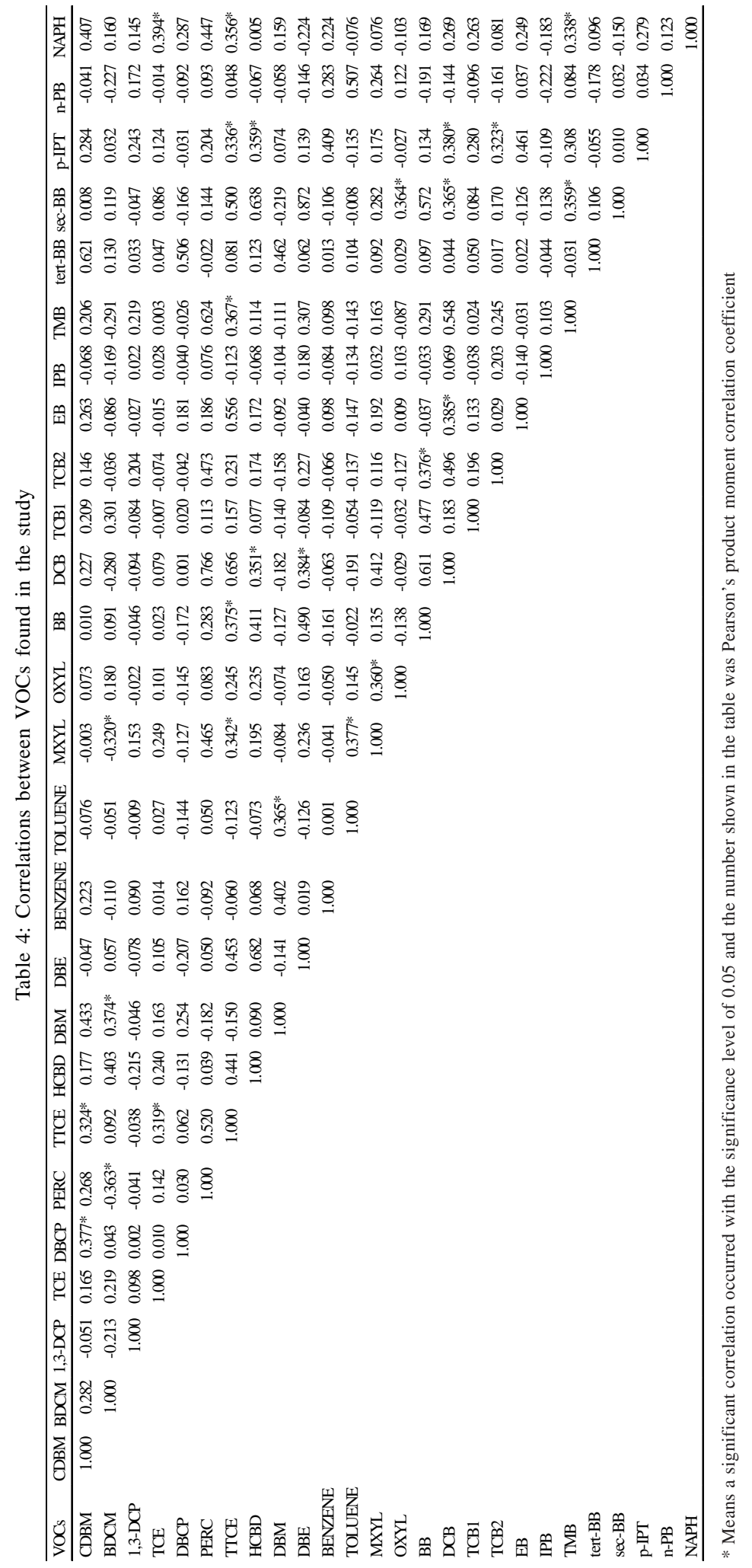


D. F. Juang et al.

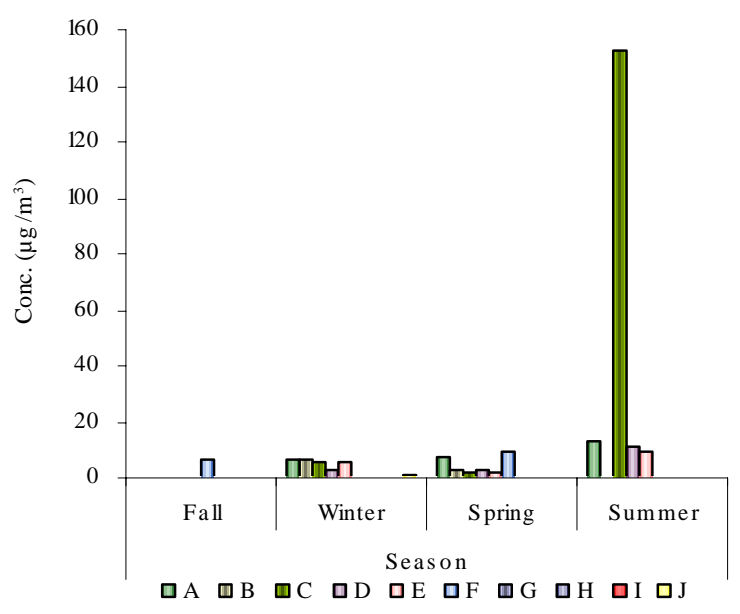

(a) Benzene

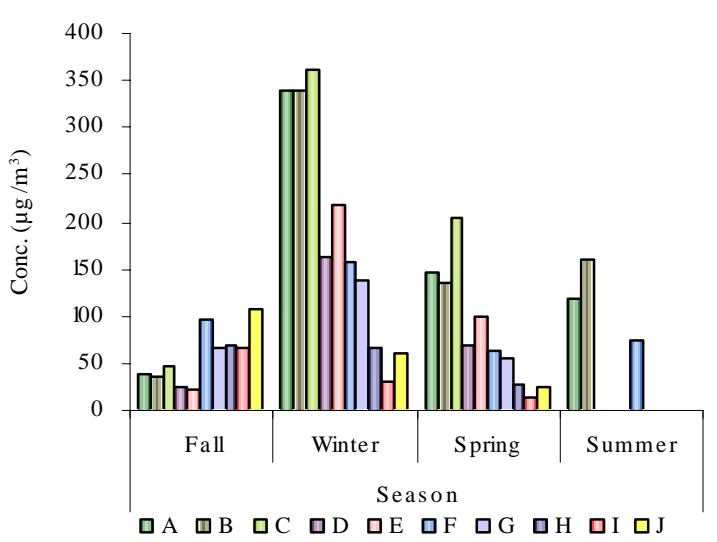

(c) sec-butylbenzene

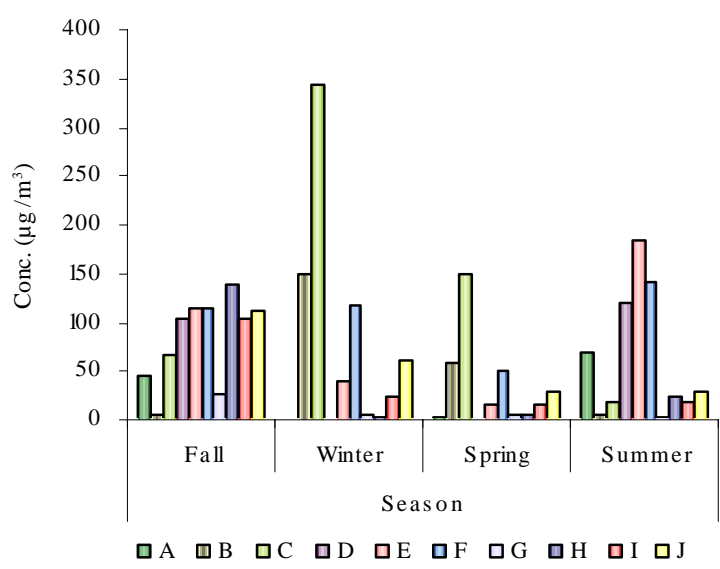

(e) 1,2-dichlorobenzene

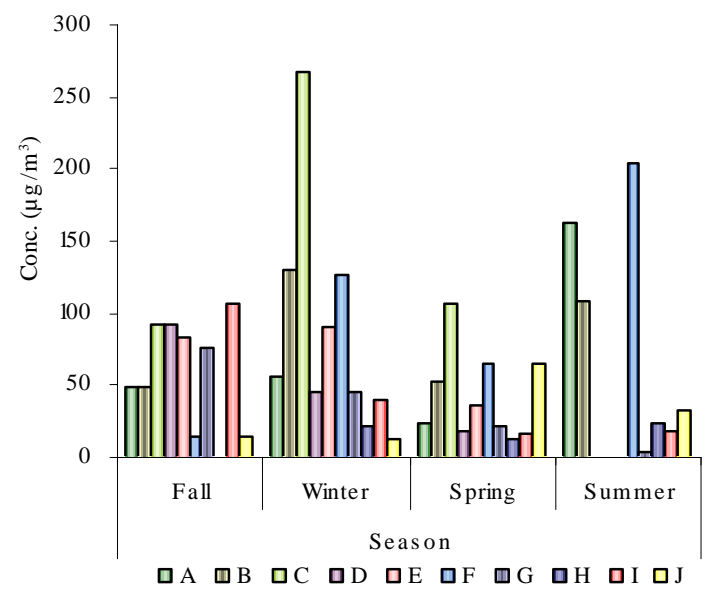

(b) Bromobenzene

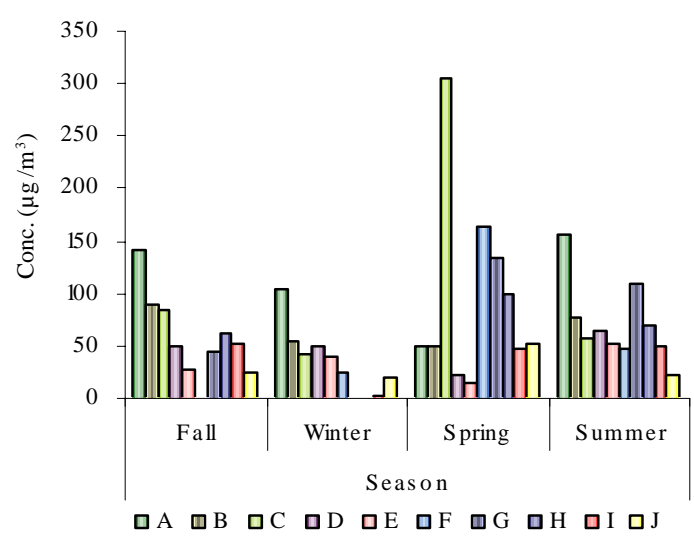

(d) tert-butylbenzene

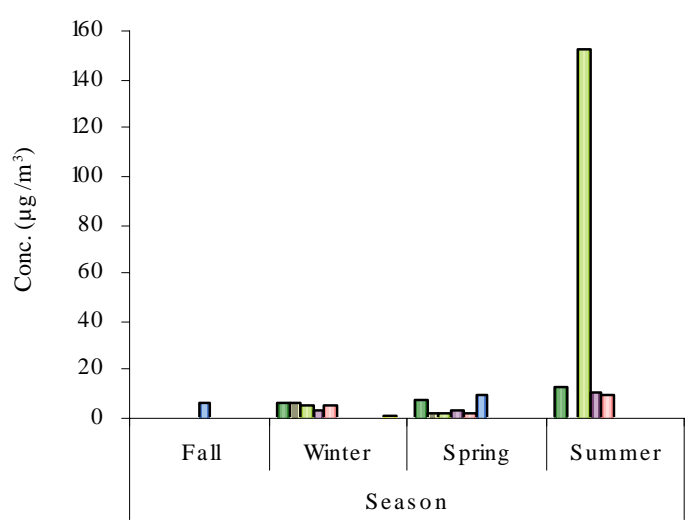

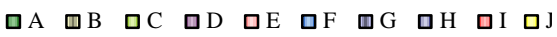

(f) Ethylbenzene

Fig. 3: Concentration distribution of benzenoic VOCs at different seasons (Note: A, B, C, D, E, F, G, H, I and J are the sampling locations shown in Fig. 1) 


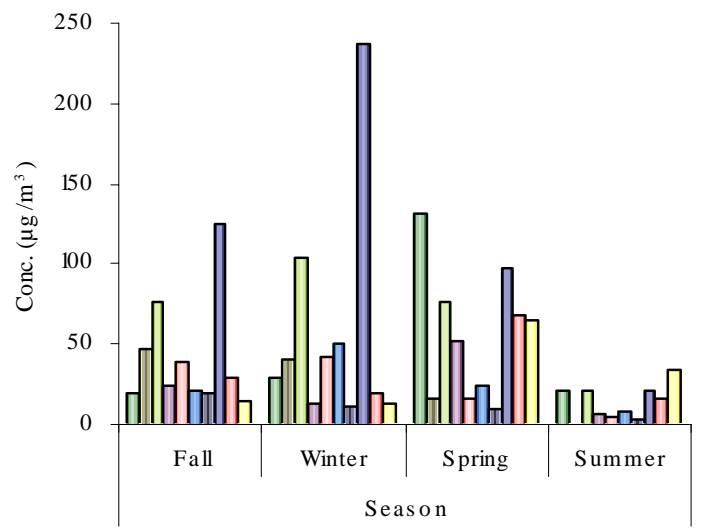

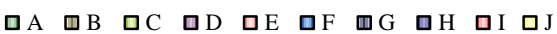

(g) Isopropylbenzene

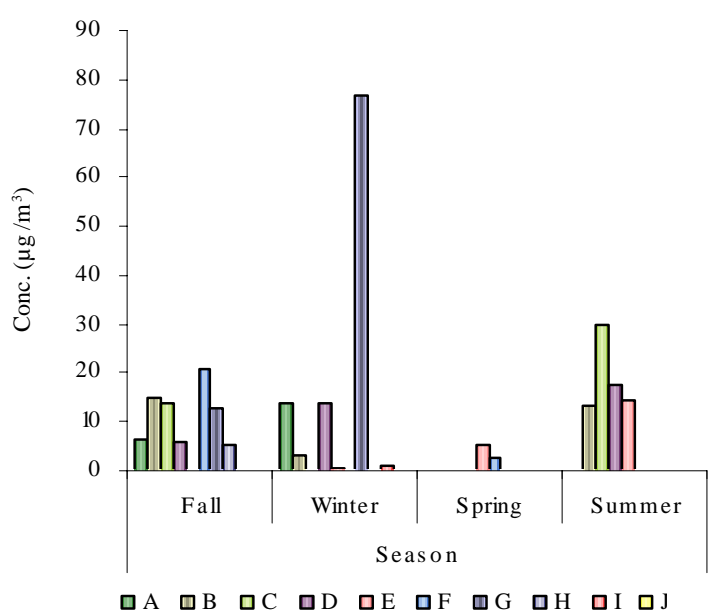

(i) n-propylbenzene

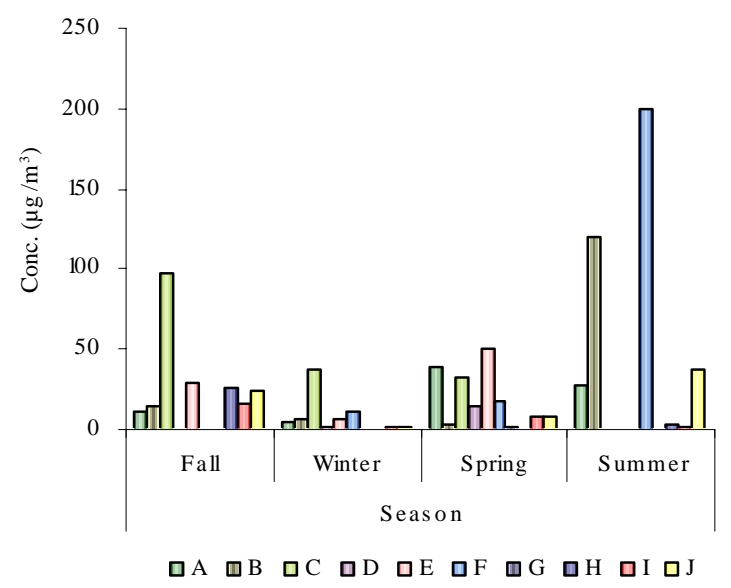

(k) 1,2,3-trichlorobenzene

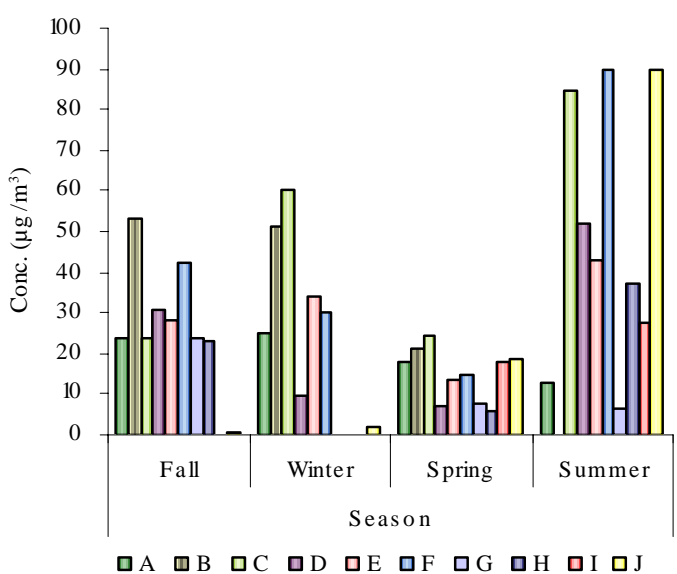

(h) p-isopropyltoluene

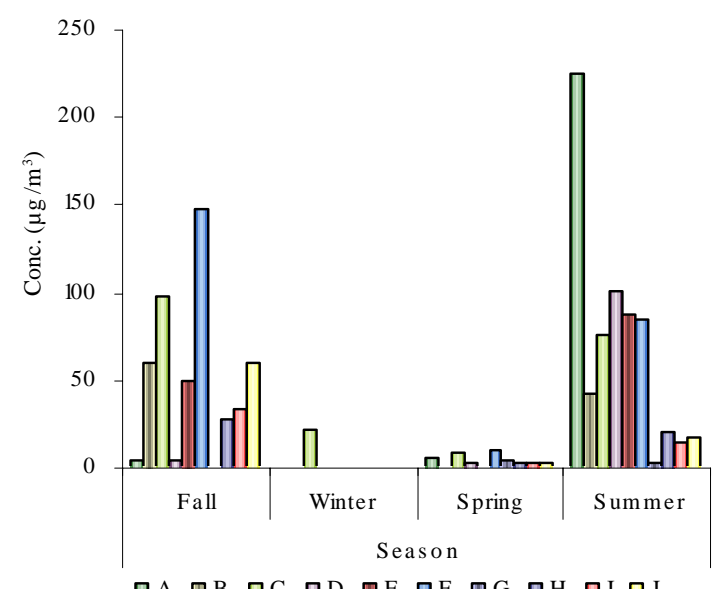

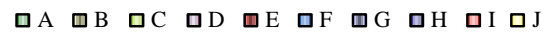

(j) Naphthalene

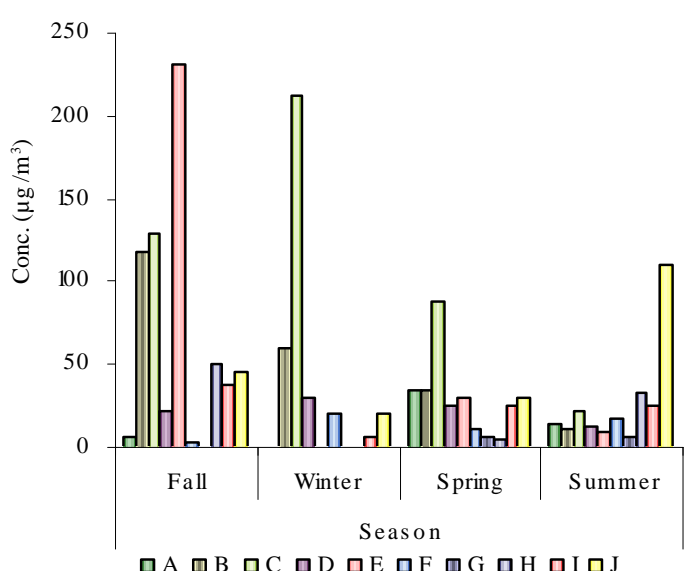

(l) 1,2,4-trichlorobenzene

Fig. 3 (continued): Concentration distribution of benzenoic VOCs at different seasons (Note: A, B, C, D, E, F, G, H, I and J are the sampling locations shown in Fig. 1) 


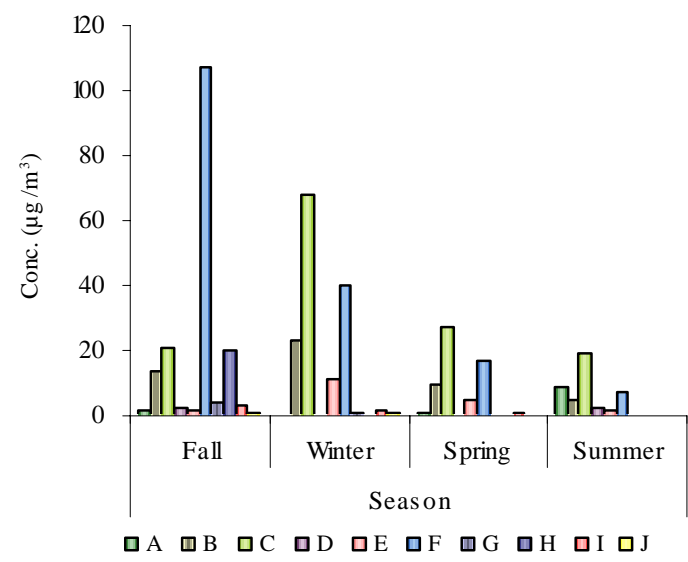

(m) 1,3,5-trimethylbenzene

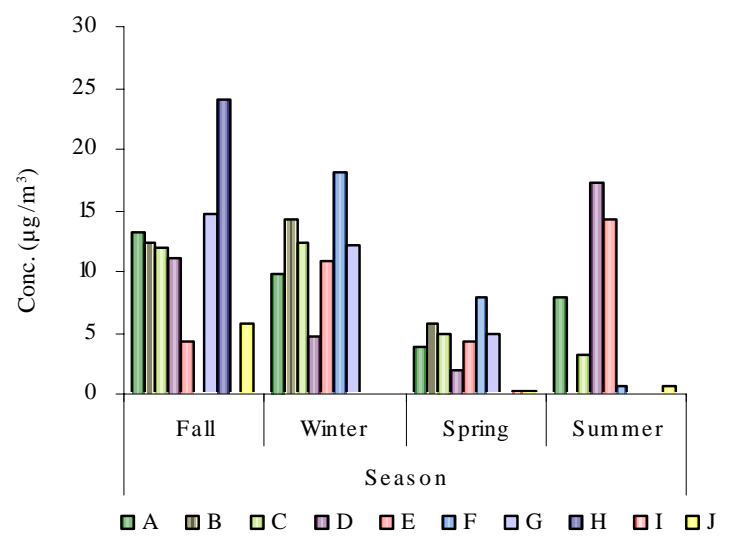

(o) m-xylene

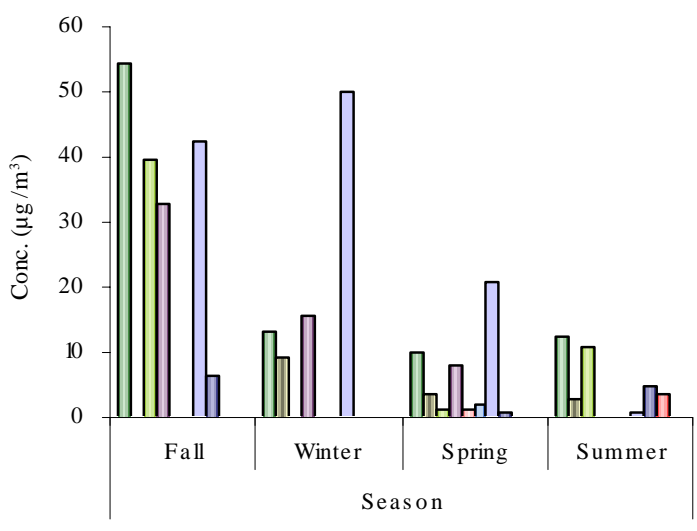

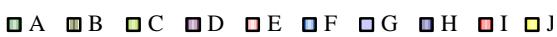

(n) Toluene

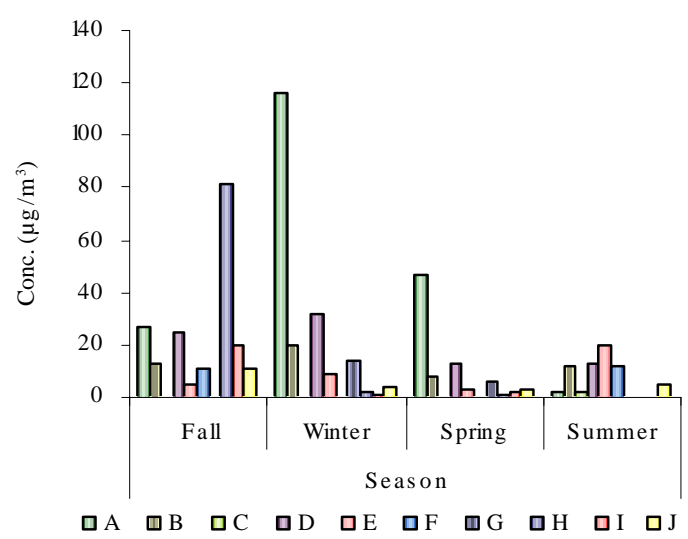

(p) o-xylene

Fig. 3 (continued): Concentration distribution of benzenoic VOCs at different seasons (Note: A, B, C, D, E, F, G, H, I and J are the sampling locations shown in Fig. 1)

(TMB), sec-butylbenzene (sec-BB) and npropylbenzene. P-isopropyltoluene (p-IPT), 1,2,3trichlorobenzene (1,2,3-TCB) and naphthalene (NAPH) showed higher concentrations in summer while bromobenzene indicated higher concentration in summer and winter. Tert-butylbenzene was found to have higher concentration, especially in spring.

The concentrations of sec-butylbenzene and tertbutylbenzene at the nearby environment were much lower than at the water surface of Fong Shan stream, however, the concentration of p-IPT was somewhat higher at the nearby environment of Fong Shan stream in summer. The concentrations of bromobenzene and isopropylbenzene were much higher in winter at the riverside of Fong Shan stream, however, the level of bromobenzene was also found to be high at the riverside in summer.

The levels of 1,2-DCB were found to be sometimes higher than $100 \mu \mathrm{g} / \mathrm{m}^{3}$ in different seasons. It has been reported that long term exposure of 1,2-DCB may cause negative effects on kidney or blood system (IPCS, 2003), although the carcinogenicity of 1,2-DCB to human is still not classifiable. NIOSH (2003) mentioned that the average level of 1,2,4-TCB in the air of urban area was about $0.76 \sim 1.28 \mu \mathrm{g} / \mathrm{m}^{3}$ in USA. 1,2,4-TCB and 1,2,3-TCB were identified with the concentrations over $100 \mu \mathrm{g} / \mathrm{m}^{3}$ at the nearby environment of Fong Shan stream, especially in 
summer for 1,2,3-TCB and in summer, fall and winter for 1,2,4-TCB.

Table 4 showed the correlations between the VOCs identified at the water surface and the nearby environment of Fong Shan stream (significance level = 0.05). Apparently, the concentrations of NAPH, TMB, pIPT, DCB, BB, MXYL, CDBM and TCE were significantly correlated with those of TTCE with the relative ratios (concentration means) of about 1: 0.47: 0.16: 0.40: 0.97: 0.97: 0.10: 1.25: 0.43 (TTCE: NAPH: TMB: p-IPT: DCB: BB: MXYL: CDBM:TCE).

The concentrations of TTCE, toluene, BDCM and OXYL were very significantly correlated with MXYL concentrations with the relative ratios of about 1: 10.17: 1.35: 6.23: 2.10 (MXYL:TTCE: Toluene: BDCM: OXYL). The concentrations of HCBD, DCB, TCB2 and TTCE were significantly correlated with p-IPT concentrations with the relative ratios of about 1: 8.57: 2.40: 1.46: 2.48 (p-IPT: HCBD: DCB: TCB2: TTCE). The concentrations of HCBD, EB, DBE, p-IPTand sec-BB were significantly correlated with DCB concentrations with the relative ratios of about 1 : 3.58: 0.11: 1.76: 0.42: 1.44 (DCB: HCBD: EB: DBE: p-IPT:sec-BB). It is also noted that DCP and IPB were the only two species without a correlation with any other VOCs.

\section{ACKNOWLEDGMENTS}

The authors would like to express their gratitude and appreciation to the National Science Council (NSC) of Taiwan for the financial support of this research.

\section{REFERENCES}

A Sewer Department of Kaohsiung Municipal Government, (2003). Report of Cheun-Tsen River Environmental Monitoring Project, Kaohsiung Municipal Government, Kaohsiung City, Taiwan.

ATSDR, (1992). US public health service, Agency of toxicity substances and disease registry. Toxicological profile for 1,2-Dibromo-3-Chloropropane, ATSDR and USPHS, USA.

ATSDR, (2005). Public health statement-bromoform and dibromochloromethane, agency of toxicity substances and disease registry, CAS No.: 75-25-2 and 124-48-1, 1-6.

Beck, B. D.; Seeley, M. R.; Tonner Navarro, L. E.; Deskin, R., (2000). Variation in cancer classification between European countries and organizations., Toxicologist, 54 (1), 273-274.

Danse, L. H.; Van Velsen, F. L.; Vander Heijden, C. A., (1984). Methylbromide, carcinogenic effects in the rat forestomach., Toxicol. Appl. Pharm., 72 (2), 262-271.

Ellis, P. A.; Rivett, M. O., (2007). Assessing the impact of VOC-contaminated groundwater on surface water at the city scale., J. Contam. Hydrol., 91 (1-2), 107-127.

IARC, (1999). Overall evaluations of carcinogenicity, Summaries and evaluations, International agency for research on cancer, 73, 223.

IPCS, (1994). Assessing human health risks of chemicals: derivation of guidance values for health-based exposure limits. International programme on chemical safety, international programme on chemical safety, environmental health criteria 170, world health organization, Geneva.

IPCS, (2003). International chemical safety cards, international programme on chemical safety, ICSC: 1066.

Kaiser, K. L. E.; Comba, M. E., (1983). Volatile contaminants in the Welland river watershed., J. Great Lakes Res., 9 (2), 274-280.

Kostopoulou, M. N.; Golfinopoulos, S. K.; Nikolaou, A. D.; Xilourgidis, N. K.; Lekkas, T. D., (2000). Volatile organic compounds in the surface waters of northern Greece., Chemosphere, 40 (5), 527-532.

Lewis, A.; Davies, J., (1998). Blue-sky chromatography: GC in flight. LC-GC Int., 11, 428-433.

Liu, Y.; Shao, M.; Lu, S. H.; Chang, C. C.; Wang, J. L.; Chen, G., (2007). Volatile organic compound (VOC) measurements in the Pearl river Delta (PRD) region, China., Atmos. Chem. Phys. Discuss., 8 (8), 1531-1545.

Nichols, J. W.; McKim, J. M; Lien, G. J.; Hoffman, A. D.; Bertelsen, S. L.; Gallinat, C. A., (1993). Physiologicallybased toxicokinetic modelling of three waterborne chloroethanes in channel catfish, Ictalurus punctatus., Aquat. Toxicol., 27 (1-2), 83-111.

Nikolaou, A. D.; Golfinopoulos, S. K.; Kostopoulou, M. N.; Kolokythas, G. A.; Lekkas, T. D., (2002). Determination of volatile organic compounds in surface waters and treated wastewater in Greece., Water Res., 36 (11), 2883-2890.

NIOSH, (2003). The registry of toxic effects of chemical substances. National institute for occupational safety and health, RTECS No.: DC2100000, CAS No.: 120-82-1.

NYSDH, (2003). Tetrachloroethene (PERC) in indoor and outdoor air, New York state department of health, fact sheet, 1-6.

OSHA, (1989). Air contaminants, final rule, federal register, occupational safety and health administration, US department of labor, 54, 2933.

Ott, M. G.; Scharnweber, H. C.; Langner, R. R., (1980). Mortality experience of 161 employees exposed to ethylene dibromide in two production units., Brit. J. Ind. Med., 37 (2), 163-168.

Rathbun, R. E., (2000). Transport, behavior, and fate of volatile organic compounds in streams., Crit. Rev. Env. Sci. Tech., 30 (2), 129-295.

Rivett, M. O.; Shepherd, K. A.; Keeys, L.; Brennan, A. E., (2005). Chlorinated solvents in the Birmingham aquifer, UK: 1986-2001., Q. J. Eng. Geol. Hydroge., 38 (4), $337-$ 350 .

Sacks, R.; Akard, M., (1994). High-speed GC analysis of VOCs: tunable selectivity and column selection., Environ. Sci. Tech., 28 (9), 428A-433A.

Singh, H. B.; Salas, L. J.; Stiles, R. E., (1982). Distribution of selected gaseous organic mutagens and suspect carcinogens in ambient air., Environ. Sci. Tech., 16 (12), 872-880.

Smith, A. D.; Bharath, A.; Mallard, C.; O., D.; Smith, K.; Sutton, J. A.; Vukmanich, J.; McCarty, L. S.; Ozburn, G. W., (1991). The acute and chronic toxicity of ten chlorinated organic compounds to the American flagfish (Jordanella floridae)., Arch. Environ. Con. Tox., 20 (1), 94-102. 
Ter Haar, G. (1980). An investigation of possible sterility and health effects from exposure to ethylene dibromide. In: Ames, B., Infante, O. and Peirtz, R. (Ed.), Ethylene dichloride: A potential health risk? Cold spring harbor, New York, cold spring harbor laboratory, 167-188.

USEPA, (1994). Determination of total gaseous organic concentration using a flame ionization analyzer, 40 CFR Method 25A, US environmental protection agency, 7-1-94 Eds.

USEPA, (1997). Risk assessment issue paper for: derivation of provisional chronic RfDs for n-butylbenzene (CASRN 104-51-8), sec-butylbenzene (CASRN 135-98-8), tertbutylbenzene (CASRN 98-06-6) and n-propylbenzene (CASRN 103-65-1). National Center for Environmental
Assessment, US Environmental Protection Agency, 97-009/ 6-5-97.

Watson, S. B.; Ridal, J.; Zaitlin, B.; Lo, A., (2003). Odours from pulp mill effluent treatment ponds: the origin of significant levels of geosmin and 2-methylisoborneol (MIB). Chemosphere, 51 (8), 765-773.

Yamamoto, K.; Fukushima, M.; Kakutani, N.; Kuroda, K., (1997). Volatile organic compounds in urban rivers and their estuaries in Osaka, Japan., Environ. Pollut., 95 (1), 135143.

Yamamoto, K.; Fukushima, M.; Kakutani, N.; Tsuruho, K., (2001). Contamination of vinyl chloride in shallow urban rivers in Osaka, Japan., Water Res., 35 (2), 561-566.

\section{AUTHOR (S) BIOSKETCHES}

Juang, D. F., Ph.D., Associate professor, Department of Health Business Administration, Meiho Institute of Technology, 24F, 230, Ming-Chuan Second Road, Kaohsiung 806, Taiwan. Email: x2060@email.meiho.edu.tw

Yuan, C. S., Ph.D., Professor, Institute of Environmental Engineering, National Sun Yat-Sen University, Taiwan, R.O.C. Email: ycsngi@mail.nsysu.edu.tw

Hsueh, S. C., M.Sc., Lecturer, Department of Health Business Administration, Meiho Institute of Technology, Taiwan.Email: x3113@mail.meiho.edu.tw

Chiou, L. J., M.Sc., Lecturer, Department of Health Business Administration, Meiho Institute of Technology, Taiwan.Email: x3175@mail.meiho.edu.tw

This article should be referenced as follows:

Juang, D. F.; Yuan, C. S.; Hsueh, S. C.; Chiou, L. J., (2008). Distribution of volatile organic compounds around a polluted river. Int. J. Environ. Sci. Tech., 6 (1), 91-104. 